J O UR N A L OF THE ROYAL SOCIETY OF MEDICINE Volume 99 October 2006

\title{
Curb your enthusiasm: undignified examinations
}

John Main

J R Soc Med 2006;99:538-538

I went to medical school without any doubts that medicine was a wonderful thing and that doctors were motivated purely by altruism. The first time I remember someone suggesting this might not be the case was a sociologist who put Ivan Illich's Medical Nemesis ${ }^{1}$ on our reading list. I was quite annoyed that anyone (especially a non-doctor) could suggest that medicine was largely a cosy job creation scheme to make doctors rich (I may be oversimplifying Illich's argument but it was along time ago and I was reading under duress). I would not have believed anyone if they had suggested that I would get it eventually.

Again, to an unquestioning youth, screening was a selfevidently good concept. I still vividly remember a lecturer taking us gradually through what needs to be true for screening to be worthwhile. It was becoming clear that things were rarely simple, and a rather more questioning attitude to received wisdom was needed. This was reinforced by increasing exposure to real doctors. Some were wonderful, but pompous self-regard and blustering ignorance were not hard to find. Even the wonderful ones largely went with the overwhelming ethos of treating patients principally as teaching materials. Depending on what was being taught, this did not necessarily matter greatly. But how could it be thought reasonable to subject people to undignified examinations, just for students to practice?

By which I largely mean, rectal examination. (In my day this was known as a PR. I note recent rebranding as DRE or digital rectal exam, the exact nature of which may come as a shock to those consumers familiar with digital TVs, phones and cameras.) One surgeon whose clinics I had the misfortune to attend insisted on the students sliding their index finger into an anus as he slid his out, as if the patient would not notice. One large working class Scot, somewhat perplexed by this practice, looked at me over his right shoulder and said, 'Son, I wouldnae hiv your job for anything'. Good point, I thought, as I sheepishly removed my finger from his bottom.

Despite my rising doubts and blossoming argumentative streak, as a surgical house officer I fell in line with the old maxim, '. . . if you don't put your finger in it you put your foot in it'. (I've mislaid my old Bailey and Love ${ }^{2}$ and therefore cannot tell you if that masterly example of surgical wisdom was attributed to the same psychopath who stated that 'big surgeons make big incisions'. I used to love that stuff, and believe it.)

And then $\mathrm{Mr}$ Scott put me right. His argument encapsulated the fundamental pointlessness of routine rectal examination, that is the inherent unlikeliness that a hurried disinterested PR by a non-expert would uncover cancers just before they passed into the incurable stage. He was not a doctor, or even a sociologist, he was an elderly demented man from Leith with an ischaemic foot. When, behind some screens in an old fashioned Nightingale ward filled with Sunday evening visitors, I discreetly suggested a PR was the perfect end to a routine surgical clerking, he put me right. 'Yer no sticking yer fucking finger up ma arse' he said. And ever since, I have split medicine into two. The things we do to treat immediate disease, and the things we do to maybe prevent disease in the future. And if we are doing the latter, let us make sure the instant pain is likely to be outweighed by the future gain. And do not believe anyone that says anything beginning with 'everyone must . . .'

\section{REFERENCES}

1 Illich Ivan. Medical Nemesis: The expropriation of health. London: Marian Boyars, 1975

2 Bailey H, Love M. Short Practice of Surgery, 17th edn. London: Hodder Arnold, 1977 